\title{
Computerized Reforestation Records for Alberta
}

\author{
A. K. Hellum ${ }^{1}$ and D. E. Ritcey ${ }^{2}$ \\ ${ }^{1}$ Dept. of Forest Science, University of Alberta, \\ Edmonton, Alberta. \\ ${ }^{2}$ Silviculture Section, Forest Division, Alberta Ener- \\ gy and Natural Resources, Edmonton, Alberta.
}

\begin{abstract}
In 1972, Alberta established a computerized record system for reforestation data to aid in monitoring and planning reforestation activities. This system provides data to guide preparation of financial estimates, help monitor operational reforestation, and aid in identifying special problem areas. Initial records indicate that reforestation in the province will reach between 80 and $90 \%$ of target objectives within the given 10-year post-cut reforestation period based on 1966, 1967, and 1968 data. However, an additional 4,000 to 8,000 ha, which accumulated annually during this period, constitute problem areas which will need special attention (treatment and planting) to reach acceptable stocking levels. This system is being widely accepted by industry and government of Alberta.
\end{abstract}

\section{Introduction}

The annual cut-over area in Alberta is increasing by about 1200 ha annually. Between 1970 and 1974 alone, it increased from 16800 to 23400 ha. Harvested areas, also called cut blocks in Alberta, averaged 12 ha in size with a range from 2 to 120 ha between 1966 and 1974. As a result, the sheer bulk of the records to be kept by the Crown required that they be computerized rather than kept manually.

About 2,500 new record sheets are now added annually, each sheet containing considerable detailed information on reforestation. Records are initiated when logging starts and are updated when treatment and regeneration survey data are collected in compliance with Provincial regulations.

The computer system that was set up in 1972 enables the Department of Energy and Natural Resources to maintain reliable records for the reforestation of all Crown lands by industry and the Alberta Forest Service as required by provincial Acts and Regulations. The system handles Timber Quota (Anon. 1972) information subsequent to May 1, 1966 and Forest Management Agreement information subsequent to 1955 . It also handles data on various minor silvicultural activities such as thinning and experimental fertilization.

The system now provides information for detailed program budgeting based on actual data rather than on estimates. It also aids in the analysis, and improvement, of reforestation methodology. Moreover, data can be provided on short notice to various interest groups: political, professional, and public.
Several larger companies now have computerized their own silvicultural records in order to enhance their own programs and to meet Provincial requirements for annual statements on reforestation progress on Crown lands.

This paper has three objectives: 1) to outline the main points of the computerized system for keeping cutting and reforestation records in $\mathrm{Al}$ berta; 2) to show how the system helps to monitor all reforestation work done on Crown lands, and 3 ) to give a summary of cutover and reforestation information for the first three-year period of the Timber Quota system.

\section{The Computerized Record System}

The basic record form is the "CS-TM09" (Fig. 1) which is called the "Cut Block and Silviculture Status Report". It serves as an input and output document in that it is filled out by the field forester or ranger, is sent to Edmonton for data punching, and is reprinted to include the field data and returned to the field forester for his records and planning uses. A manual has been prepared for use in compiling CS-TM09 forms and distributed to field staff within the Forest Service.

A unique numbering system was established for all cut blocks based on the legal survey of Township, Range, and Meridian. It is important that once established, the number does not change even if there are changes in management unit boundaries, licence boundaries, or timber permit boundaries. The legal description, plus a sequential number, is used as the cut block number. For example, the first cut block to be numbered in Township 68 , Range 4, west of the fifth Meridian would be 06804-5-0001. In any one township or range there can, therefore, be 9999 sequential or project areas.

The record form is initially printed on three-part paper in Edmonton and sent to the field forester. $\mathrm{He}$ numbers the block when harvesting has been approved. The two carbons are retained in the field for reference and the original is returned to Edmonton.

The form is now printed on four-part paper when field data are entered in Edmonton. The data are printed under or to the side of the appropriate field. Thus corrections and additions to existing forms can clearly and easily be made. One of the new carbon copies of this form is retained in Edmonton and the three other copies are returned to the field. Old field carbon copies are then destroyed and new forms filed in their stead. When, for a given cut block, more data become available, or corrections are to be made, forms are again sent to Edmonton from the field with the new or changed information being entered on the old data form. 
Space does not allow a detailed description of all fields and their appropriate codes, but some main ones will be described. Other information can be obtained from the authors.

When a cut block is approved for harvest, the sequential number is allocated (field 3 ). Next, the particular Management Unit, Quota and Timber Licence, and reforestation responsibility are entered (fields $07,08,11,12,13$ ).

Data on cut block size and location are then entered on the form (fields 15-30 incl.). Cut blocks which straddle township and/or range boundaries are numbered as if they fell into that township into which the larger part of the block falls (field 15). Other parts of the block area are then identified by location (in fields 19, 23, and 27) and by area (fields 22, 26, and 30 ).
If the original cut block areas prove too difficult or too expensive to reforest, alternate areas may be chosen to be treated. Form space is also allocated for this area description (fields 31-46 incl.).

The record type is noted to show whether this is a cut block, a seed production area, an experimental project etc. The sequence or history of harvesting operations is also recorded (fields 48,49 , $50,52,53$ ). Harvest history indicates year of harvest approval year of commencement of harvesting, year of completion of harvest, and year of cut block clearance as well as the harvesting method and slash disposal treatment used. Cut block clearance is granted by the Crown for cut blocks which have been logged according to plan and have been treated to reduce slash hazard and landing debris accumulations.

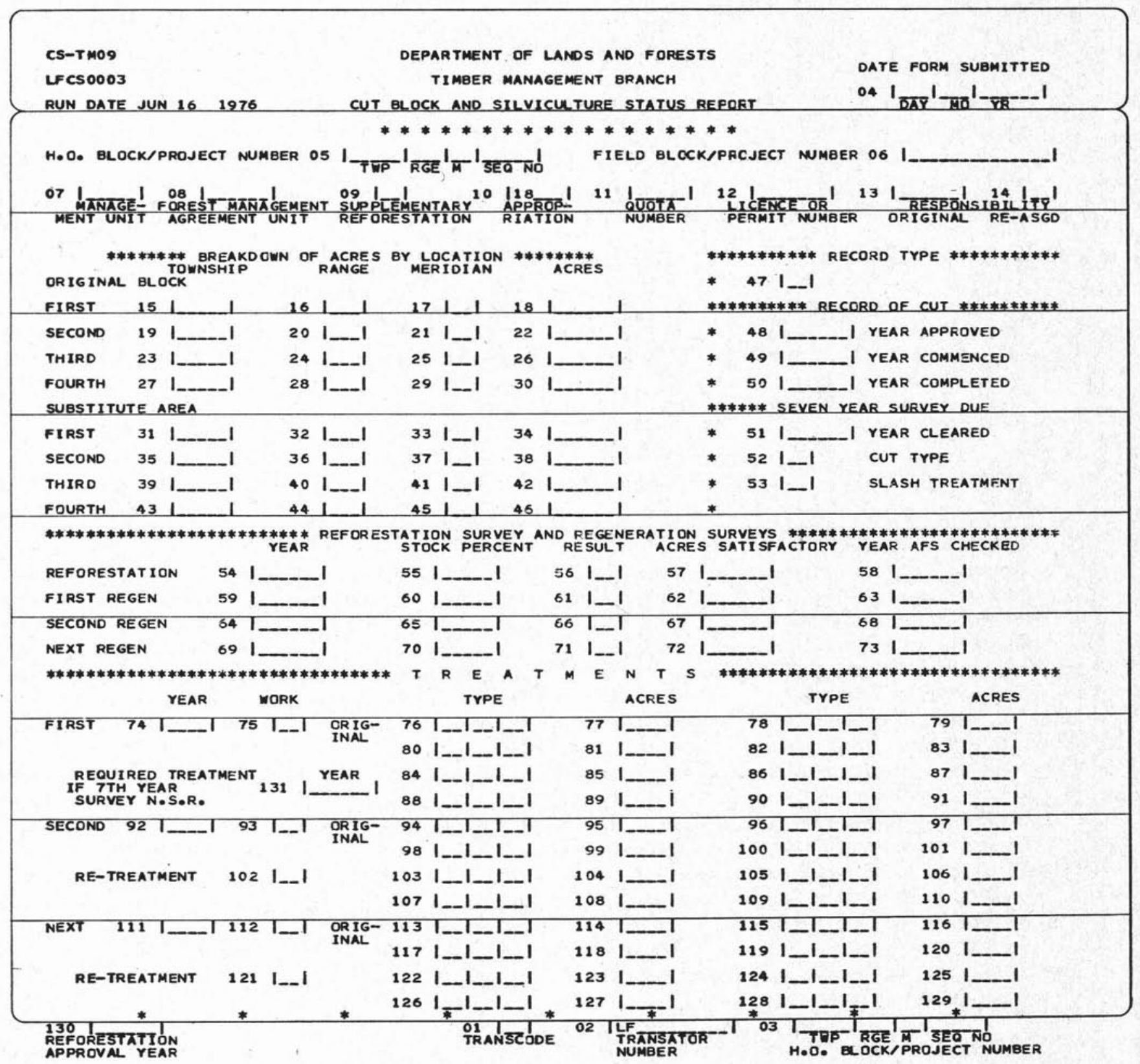

Fig. 1. The basic record form, CS-TM09, used in keeping reforestation records. 
The data form has room for information on as many as four different regeneration surveys (fields $54-73$ ) recording for each the year of survey, stocking per cent, hectares S. R. (Satisfactorily Restocked), and the year that the Alberta Forest Service check-surveyed the unit (if this was done). The seven-year survey-due-date is printed automatically below field 49 when field 49 (year harvesting commenced) is filled in.

Reforestation treatment data are recorded next (fields 74-129). In order to maintain an accurate picture of treatment activity space has been allocated for a four-way breakdown of each treatment occurrence (fields 76, 78, 80, and 82 ). Each occurrence can be broken down into a maximum of three combinations of treatment type. For example, in 1974 cut block 068-04-5-0001 of 100 ha (field 18) might have had 75 ha scarified (field 77), of which 25 ha were planted (field 79), and 50 ha were seeded (field 81 ), while 25 ha remained untreated (field 83 ). The scarification may have been done by machine (coded as $X M$ in field 76), the seeding may have been by helicopter (coded as $\underline{S} \underline{A}$ in field 78), the planting may have been by hand using containers (coded $\underline{P} \underline{H} \underline{C}$ in field 80 ), and the untreated portion was coded as $U$ _ (in field 82).

In the "second" and "next" treatment fields (92 and 111) retreatment data are recorded and detailed as above for original treatments (fields 92110 incl. and 111 - 129 incl.).

If, or when, all four fields for regeneration survey data and all three fields for treatment data have been filled in, new information must be recorded in Next Regeneration (69) or Next Treatment (111) fields and the original document filed together with the replacement document to keep a record of all surveys and treatments.

Up to 1975 , individual record sheets had been established for 16,000 cut blocks. Only a limited number of documents has been established to date for areas other than cut blocks.

\section{Data Summaries Help Monitor Reforestation Progress}

1. Reforestation data can be summarized by year of timber harvest to ensure that cut blocks do not remain unregenerated for more than the prescribed 10 years (Timber Management Regulations, 1973). Such data can be summarized by Cut Block, Forest District, Management Unit, and Reforestation Responsibility. Data are detailed by treatment and survey.

2. Reforestation data can also be summarized by reforestation treatment year rather than by year of harvest. Thus information can be made available for the preparation of annual departmental reports, for budgetary reasons for individual forest regions, and for planning functions and budget control at Provincial Headquarters.

3. Regeneration survey information can also be summarized, by timber licence, to ensure that cut blocks are surveyed within the prescribed time limits of 7 and 10 years after harvest to meet requirements under the Timber Management Regulations (1973). This same routine can be used to provide listings of all survey requirements regardless of age of cut block.

4. Data on N.S.R. (Not Satisfactorily Restocked) acreage are also summarized by timber licence and can be obtained for all ages of cutovers.

5. In order to maintain control and avoid issuance of cutting clearances on too many blocks per year, in view of the considerable carry-over of harvesting on many cut blocks from year to year, a routine was set up to answer the following questions:

i) On how many cut blocks has harvesting been approved but not yet commenced?

ii) On how many cut blocks has harvesting commenced but not been completed?

iii) How many cut blocks have been harvested completely but have not yet been cleared by woods inspection?

The last three programs $(3,4$, and 5$)$ provide a means of cut control for both field and headquarters staff. They ensure that cut blocks cannot be overlooked, as might easily happen if records were kept manually.

The CS-TM09 system can also be used to keep records on thinnings, seed production areas, stand conversion projects, wildlife reforestation projects, other research projects, and reforestation of old N.S.R. areas simply by changing the code in field 47 (Record Type). Summary programs have also been written to provide yearly area totals for these various activities.

\section{Cutover and Reforestation Information}

\section{Stockings Status of Harvest Areas}

Although the following data pertain only to operations carried out on areas harvested between May 1, 1966 and April 30,1969, they do indicate what the new record system can provide. At this point the system contains complete survey information on stocking for 1966-7, 1967-68, and 1968-69 of the current harvest period (1966-1976) ${ }^{3}$.

Harvesting information for this period is given in Table 1.

Of the 5561 ha to be reforested by the Province, $60.4 \%$ was S.R. by the end of the seventh year after cut and $39.6 \%$ remained as N.S.R. Forest Management Agreement Holders had achieved S.R. status on $57.4 \%$ of their cut-over of 13786 ha, and Quota Holders had achieved $52.1 \%$ S.R. status on their 16012 ha by the same time. These values are based on survey records for $80 \%$ of the total cut-over for these three years ${ }^{4}$.

\footnotetext{
Section 132 of the Timber Management Regulations states: "Considering the year of cut as being the first year, a licensee or holder of a forest management agreement shall complete and submit to the Minister a reforestation survey which meets the specifications of the Minister by the end of the seventh year for all areas he is obliged to reforest."

4Between May 1976 and December 1976, 97.5\% of the survey records were entered on computer. However, only the first $80 \%$ have been used for
} detailed calculations. 
The rate of S.R. increases over time (Fig. 2) is indicative of the following important influences.

1. Timing of survey in relation to harvest and subsequent treatment. Some areas were treated shortly after cutting while others were treated so recently that they have not been surveyed to assess the latest treatment.

2. Varying amounts of advance growth less than 30 years old remain after logging, especially in the Mixedwood areas of Alberta. This stocking would show up in early surveys of cut units not yet treated. However, this residual material will decrease sharply with the trend towards mechanization of logging and the lowering of stump diameter limits.

3. The increases in S.R. areas after 1972/73 reflect

Table 1 - Total cut-over area for the first three years of the Quota period in Alberta, (1966-1968 inclusive) broken down by agency responsibility for reforestation.

\begin{tabular}{lcc}
\hline $\begin{array}{l}\text { Agency responsible } \\
\text { for reforestation }\end{array}$ & $\begin{array}{c}\text { Areas } \\
\text { harvest (ha) }\end{array}$ & $\begin{array}{c}\text { Percentage of } \\
\text { total }\end{array}$ \\
\hline $\begin{array}{l}\text { The Province is respon- } \\
\text { sible for reforestation }\end{array}$ & 5561 & \\
on................ & & 15.7 \\
$\begin{array}{l}\text { Forest Management } \\
\text { Agreement Holders (F. }\end{array}$ & 13786 & 39.0 \\
$\begin{array}{l}\text { M.A.'s) have to reforest } \\
\text { Qua Holders have } \\
\text { agreed to reforest....... }\end{array}$ & 16012 & 45.3 \\
\hline \begin{tabular}{l} 
For a total of............. \\
\hline
\end{tabular} & 35359 ha & $100.0 \%$ \\
\hline
\end{tabular}

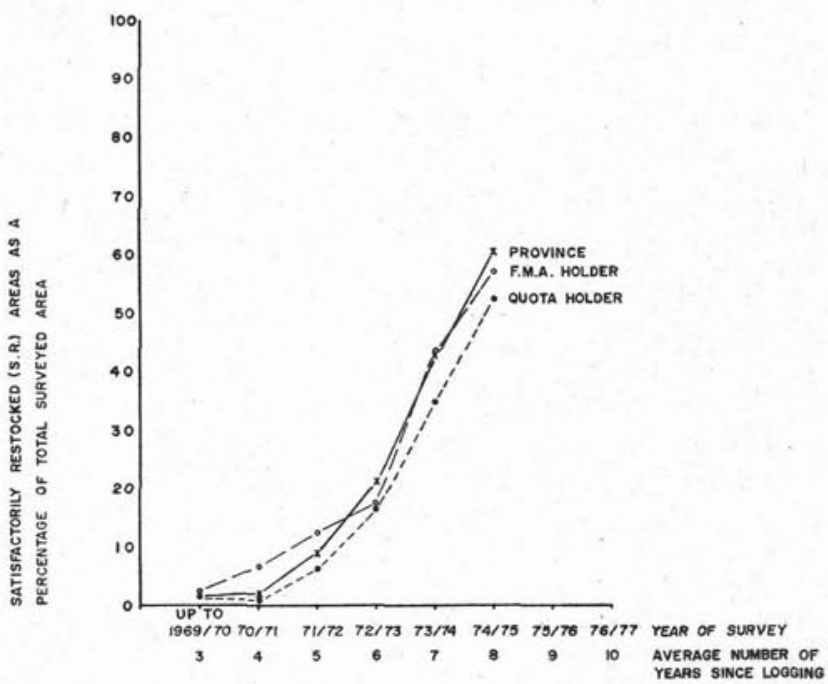

Fig. 2. Cumulative curves depicting the area of cut which is satisfactorily / not satisfactorily restocked judging by most recent survey data. the beneficial effects of treatment carried out before 1970 where planting and seeding were carried out immediately after harvesting.

\section{Reforestation Treatment Records}

Reforestation data for the first three years of the Quota period are shown in Table 2. It is the practice in Alberta to seed and/or plant on scarified ground. Scarified areas not directly seeded or planted are left to regenerate naturally from adjacent trees. Thus the seeded or planted areas listed in Table 2 also indicate that they have been scarified.

Therefore, only $44.8 \%$ of the cut-over for these three years has been scarified (15 855/35 359 hasee Table 2) to establish stocking either artificially (direct seeding or planting) or combined with natural seeding. Of the treated area (15 $855 \mathrm{ha}$ ), only $11.5 \%$ was direct seeded, $13.8 \%$ planted and $74.7 \%$ left to seed in naturally from adjacent stands. This reliance on natural seeding may change because of poor results. Although most areas may eventually regenerate themselves, forest managers in Alberta are not prepared to wait for this to happen. Therefore, many areas will be planted to meet reforestation deadlines.

Departmental records show that industry has achieved $71.2 \%$ success (S.R. status) with their artificial reforestation for the first three Quota years compared with $70.6 \%$ S.R. success for cutovers treated by the Province. These values include an undetermined amount of natural regeneration which has not been quantified to date.

In spite of these similarities in results it is important to realize that some forest sites, particularly in northern Alberta, are very difficult to reforest by current methods (Anon. 1975) and are therefore very expensive. Wet spruce sites are the most difficult of all to reforest and the records have shown where these areas are located in Alberta.

Finally, in order to calculate from these data what work still has to be done to achieve complete S.R. status, data for both treated and untreated areas had to be analyzed in relation to existing regeneration survey information. Table 3 shows this information as it relates to the 15745 ha which were classed N.S.R. by the most recent survey, and the areas for which records are complete.

Table 3 shows that there is considerable lag between the time that a block is cut and the time it

Table 2 - Cut areas for the first three Quota years, some of which have been treated to establish regeneration.

\begin{tabular}{|c|c|c|c|c|c|}
\hline Agency & $\begin{array}{l}\text { Total } \\
\text { area cut } \\
(\text { ha })^{*}\end{array}$ & $\begin{array}{l}\text { Total } \\
\text { scarified } \\
\text { area (ha) }\end{array}$ & $\begin{array}{l}\text { Direct } \\
\text { seeded } \\
\text { area (ha) }\end{array}$ & $\begin{array}{l}\text { Machine } \\
\text { or hand } \\
\text { planted } \\
\text { area (ha) }\end{array}$ & $\begin{array}{l}\text { Natural } \\
\text { seeding } \\
\text { (ha) }\end{array}$ \\
\hline 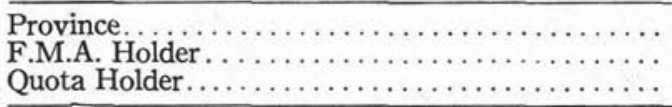 & $\begin{array}{r}5561 \\
13786 \\
16012\end{array}$ & $\begin{array}{l}2090 \\
6064 \\
7701\end{array}$ & $\begin{array}{r}1254 \\
300 \\
269\end{array}$ & $\begin{array}{r}320 \\
1587 \\
281\end{array}$ & $\begin{array}{r}516 \\
4177 \\
7151\end{array}$ \\
\hline 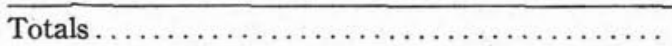 & 35359 & 15855 & 1823 & 2188 & 11844 \\
\hline
\end{tabular}

*) by reforestation responsibility. 
has been treated and documented. A total of 4,575 documents, or about $13 \%$ of all records for the first three quota years, had not been completed even seven years after harvesting. This slow data flow was remedied over the next 18 months but shows that records flow requires constant attention and upgrading.

This table also illustrates that over $15 \%$ of treated areas need retreatment after first treatment failures. These values are inflated to the extent that whole cut blocks are classed as N.S.R. until all parts are adequately reforested even when only small parts of blocks may be N.S.R. in reality. This is a book keeping problem.

Table 3 - An analysis of reforestation workload for areas harvested between May 1, 1966 and April 30, 1969.

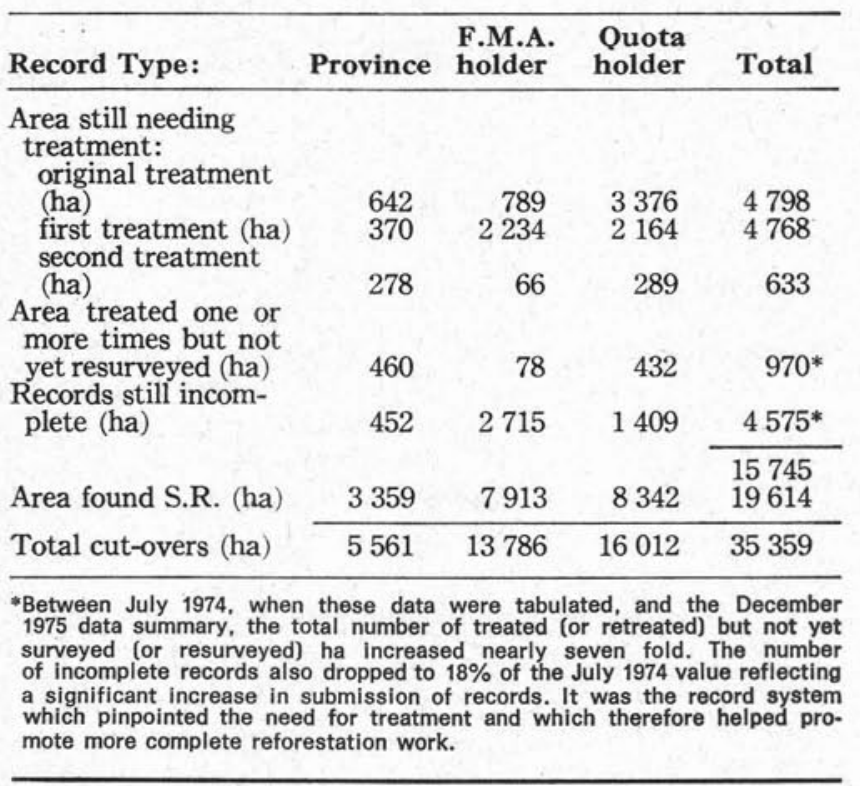

Table 3 also shows that any record system will have certain waiting periods built into it. Harvested areas are first surveyed, then treated (if needed), then left for at least three years before next survey, and then retreated (if needed) and resurveyed (if needed). This process therefore renders records incomplete for long periods of time during which only partial information on reforestation is available.

\section{Conclusions}

In Alberta, the forest industry has been responsible for reforestation of most areas harvested since 1966. However, the Province has also reforested a substantial area for Quota Holders (Anon. 1973). With this work, and an accelerating reforestation program now underway, it became essential to establish a record system to document all reforestation work. This system serves the government and industry alike and thus protects the public interest in renewable resource management.

This record system is now yielding meaningful and up-to-date information on reforestation progress. In brief, it satisfies five needs:
1. The need to meet reforestation deadlines, as indicated by the Timber Management Regulations (1973), can be satisfied through the orderly storage and retrieval of computerized data. The field forester can handle large volumes of field data and can keep order even in the most complex reforestation data for individual cut blocks. This work could not be accomplished manually.

2. The need to know how well reforestation is accomplished both regionally and provincially can be met using the periodic data summaries. (Fig. 2) shows how well the reforestation deadline of 10 years $^{5}$ is being met and that at least $85 \%$ of all cut-overs from 1966 to 1969 will probably be adequately stocked within the specified period. The data also show where the remaining $15 \%$ of the areas are which require special reforestation measures. Thus proper budget allocations can be made to look after these problem areas.

3. Field foresters need to know whether or not current reforestation methods meet reforestation needs. The system provides this information.

4. The forester prepares annual financial estimates and for this he needs data to support requests for funds. The system provides a sound statistical basis for these estimates which previously were based on partial or subjective data.

5. Finally, the forester needs complete and updated information at his disposal to plan his reforestation work, evaluate results, prepare financial estimates, and provide information to interested parties. The system now also provides this.

SSection 134 of the Timber Management Regulations states: "Considering "Section 134 of the Timber Management Regulations states: year, the Minister decides that the new growth of tree seedlings is below the required standard, the licensee or holder of a forest managemement agreement shall carry out within the following year all the operations necessary to reforest to the required standard by the end of the 10th year".

\section{Acknowledgments}

Sincere appreciation is extended to Mr. F. Bachor, Computer Systems Branch, Alberta Energy and Natural Resources for his help in establishing the computer program and to $\mathrm{Mr}$. L. Bérubé, Forest Technician, for the necessary data compilation.

\section{References}

Anon. 1972. The quota system of timber disposal. Alberta Forest Service, Alberta Lands and Forests.

Anon. 1973. Timber management regulations, Alberta Regulation 60/73, 21 pp, Queen's Printer, Edmonton, Alberta.

Anon. 1975. Scarification in reforestation. Alberta Energy and Natural Resources, Alberta Forest Service. 